\title{
Synovial fluid-derived synovial fragments represent an improved source of synovial mesenchymal stem cells in the temporomandibular joint
}

\author{
YU YAO ${ }^{1 *}$, ZHENG-YU LI $^{2 *}$, HONG ZHANG $^{1}$, YOU-HUA ZHENG ${ }^{1}$, LI-XIANG MAI ${ }^{1}$, \\ WEN-JING LIU $^{3}$, ZHI-GUANG ZHANG ${ }^{1}$ and YANG-PENG SUN ${ }^{1}$ \\ ${ }^{1}$ Guanghua School of Stomatology, Hospital of Stomatology, Sun Yat-sen University, \\ Guangdong Provincial Key Laboratory of Stomatology, Guangzhou, Guangdong 510055; \\ ${ }^{2}$ Department of Neurology, The Second Affiliated Hospital of Nanchang University, Nanchang, \\ Jiangxi 330046; ${ }^{3}$ Stomatological Hospital of Guangdong Province, Affiliated to Southern Medical University, \\ Guangzhou, Guangdong 510280, P.R. China
}

Received October 8, 2016; Accepted October 2, 2017

DOI: $10.3892 / \mathrm{ijmm} .2017 .3210$

\begin{abstract}
Surgery-obtained synovium specimens (SSSs) can provide a source of synovial mesenchymal stem cells (SMSCs) for experimental studies. However, these specimens contain diverse tissues, including the intima and subintima; therefore, these SMSCs are not entirely derived from the intima and their cell source is heterogeneous. The present study isolated synovial fragments (SFs) from synovial fluid dilutions extracted from patients with temporomandibular joint (TMJ) osteoarthrosis. Unlike SSSs, SFs, which are membranous and translucent, consist of only several cell layers, indicating the presence of only the intima. In the present study, SF cells (SFCs) and SSS cells (SSSCs) exhibited a homogeneous, fibroblast-like, spindle-shaped morphology after passaging in vitro. Furthermore, both cell types exhibited similar proliferative and differentiation potentials in vitro. However, SFCs exhibited more uniform surface markers compared with SSSCs when analysed by flow cytometry. Taken together, these
\end{abstract}

Correspondence to: Professor Zhi-Guang Zhang or Dr Yang-Peng Sun, Guanghua School of Stomatology, Hospital of Stomatology, Sun Yat-sen University, Guangdong Provincial Key Laboratory of Stomatology, 56 Lingyuan West Road, Guangzhou, Guangdong 510055, P.R. China

E-mail: kouqiangzzg@hotmail.com

E-mail: sunyp6@mail.sysu.edu.cn

${ }^{*}$ Contributed equally

Abbreviations: MSCs, mesenchymal stem cells; SSMSCs, synovium specimen-derived mesenchymal stem cells; SSSs, surgery-obtained synovium specimens; SSSCs, surgery-obtained synovium specimen cells; SFs, synovial fragments; SFCs, synovial fragment cells; SMSCs, synovial mesenchymal stem cells; ISCT, International Society for Cellular Therapy

Key words: mesenchymal stem cell, temporomandibular joint, synovial fluid, synovium results indicated that SFs contained a greater amount of unmixed intima than SSSs, and that SFCs exhibited more homogeneous characteristics than SSSCs, thereby offering an improved source of SMSCs in the TMJ.

\section{Introduction}

Mesenchymal stem cells (MSCs) are non-hematopoietic, self-renewing cells that are capable of clone-forming and multilineage differentiation (1). MSCs have been detected in numerous adult tissues, including bone marrow, skeletal muscles, adipose tissues, synovial fluid and synovium (2-5). The presence and characteristics of MSCs in synovium specimens were first reported by De Bari et al (6) and have been studied extensively in recent years (7-13). Synovium specimen-derived MSCs (SSMSCs) have a higher proliferative capacity and chondrogenic potential than MSCs derived from other sources; therefore, these cells are regarded as a promising cell source for MSC-based therapeutic strategies used to treat cartilage damage $(5,11,14-17)$.

Generally, synovium specimens are obtained through surgery, including open surgery or arthroscopic surgical procedures (18-21). Previous studies have demonstrated that MSCs can be isolated from surgery-obtained synovial specimens (SSSs) using the same protocol as that employed for synovial fibroblast cultivation. These cells exhibit ultrastructural and morphological features similar to those of type B synoviocytes $(6,22)$. However, SSS cells (SSSCs) exhibit heterogeneity. For example, Harvanova et al (19) reported that $40-50 \%$ of SSSCs are cluster of differentiation (CD) $105^{+}$subpopulation cells prior to immunomagnetic separation. These data suggest that SSMSCs correspond to a subset of adherent cells in SSSs.

SSSs generally consist of at least two anatomically distinct layers: The synovium (intima) and the underlying layer (subintima). However, since there is currently no effective method for the separation of these two tissue layers, SSMSCs reported in previous studies were not entirely derived from the intima $(5,6,9)$. Furthermore, no specific marker of synovial MSCs (SMSCs), which are derived from the intima only, 
has been identified to date. Therefore, the characteristics of SMSCs remain poorly understood.

The present study isolated and characterized synovial fragments (SFs) present in synovial fluid dilutions extracted from patients with temporomandibular joint (TMJ) osteoarthrosis. These synovial fluid-derived SFs consisted of several cell layers, indicating that they originated from the intima. Subsequently, the histological characteristics of SFs were compared with those of SSSs. Following isolation and expansion in vitro, the characteristics of both cell types were investigated, including in vitro proliferation and morphology, surface marker expression, and multilineage differentiation capabilities.

\section{Materials and methods}

Ethics statement. The present study was approved by the Institutional Ethics Board of the Hospital of Stomatology, Sun Yat-sen University (Guangzhou, China). Written informed consent was obtained from all subjects.

Collection of SFs and SSSs. SFs were collected, between October 2014 and April 2016, during TMJ arthrocentesis from patients with TMJ osteoarthrosis that showed no response to conservative treatment. Briefly, a no. 8 needle was punctured into the upper joint compartment. A total of $2.0 \mathrm{ml}$ lidocaine was infused and then withdrawn. Diluted synovial fluid samples were collected from $~ 800$ patients (age, 16-68 years), and SFs were obtained from 17 of these samples. These 17 patients (age, 18-61 years) had no other systemic diseases; among these patients, 3 were male and 14 were female. In addition, $8 \mathrm{SSSs}(\sim 0.3 \times 0.5 \mathrm{~cm})$ were obtained aseptically from patients with TMJ osteoarthrosis at the time of surgical debridement treatment for osteoarthrosis or joint disk perforation. The 8 donors (age, 25-50 years) had no other systemic diseases; among these patients, 1 was male and 7 were female.

Culture of human SFCs and SSSCs. SFs from the synovial fluid were washed three times and were then digested with $4 \mathrm{mg} / \mathrm{ml}$ type I collagenase for $2.5 \mathrm{~h}$ at $37^{\circ} \mathrm{C}$. The specimens were dispersed by pipetting and then filtered through a 200-mesh screen. Cells were centrifuged at $300 \mathrm{x}$ g at room temperature for $5 \mathrm{~min}$ and cultured with complete culture medium $[\alpha$-minimum essential medium ( $\alpha$-MEM)] supplemented with $10 \%$ fetal bovine serum (FBS) and 1X GlutaMAX (all Gibco; Thermo Fisher Scientific, Inc., Waltham, MA, USA) at $37^{\circ} \mathrm{C}$ in $5 \% \mathrm{CO}_{2}$. The SSSCs were isolated and cultured in the same manner as the SFCs.

Surface antigen expression profile. A total of 3 SFs and 6 SSSs samples were employed for surface antigen expression analysis. For surface marker detection, 300,000 dissociated cells were collected. Following incubation with primary antibodies or isotype control antibodies for $30 \mathrm{~min}$, the cells were centrifuged at $300 \mathrm{x} \mathrm{g}$ at room temperature for $8 \mathrm{~min}$. The supernatant was discarded prior to resuspension of the cells. Flow cytometric analysis was performed using an FC 500 flow cytometer (Beckman Coulter, Miami, FL, USA), and the results were analysed using MXP Software version 2.0 (Beckman Coulter). The antibodies used are listed in Table I.
Cells obtained from 3 SFs and 3 SSSs (samples 4-6) were used for subsequent experiments.

Cell proliferation assay. SFCs and SSSCs derived from 3 samples were mixed and seeded in 96-well plates at a density of 800 cells/well at passage 4 .

Cell proliferation was evaluated using Cell Counting kit-8 (Shanghai Yeasen Biotechnology Co., Ltd., Shanghai, China). The reagent was employed with the concentration of $10 \%$ per well. Culture medium with the reagent served as a blank control. The optical density (OD) of the supernatant was measured using a microplate reader (Infinite 200; Tecan Group, Ltd., Männedorf, Switzerland) after a 2-h incubation at $37^{\circ} \mathrm{C}$. Repeated measurements $(n=3)$ were conducted at each time point. The population doubling (PD) and doubling time (DT) were evaluated using the following formulas: $\mathrm{PD}=(\ln \mathrm{N}-\ln \mathrm{N} 0) / \ln 2$ and $\mathrm{DT}=\mathrm{T} / \mathrm{PD} . \mathrm{N}, \mathrm{OD}_{\text {cells }}-\mathrm{OD}_{\text {blank control }}$ at the end point; $\mathrm{N} 0, \mathrm{OD}_{\text {cells }}-\mathrm{OD}_{\text {blank control }}$ at the initial time point; $\mathrm{T}$, time interval; $\ln \mathrm{N}=\log (\mathrm{e}, \mathrm{N})$.

Colony-forming assay for SFCs and SSSCs. SFCs and SSSCs (passage 4) were plated at a density of 5 cells $/ \mathrm{cm}^{2}$. After culturing in complete medium for 2 weeks, the cells were fixed in $4 \%$ paraformaldehyde for $10 \mathrm{~min}$ at room temperature and were then stained with $0.5 \%$ crystal violet for counting.

\section{Differentiation of isolated SFCs and SSSCs.}

Osteogenic differentiation. Cells were seeded at a density of 5,000 cells $/ \mathrm{cm}^{2}$ in 6 -well plates and were induced to differentiate the next day. The differentiation medium consisted of high-glucose Dulbecco's modified Eagle's medium (H-DMEM) containing 10\% FBS (both Gibco; Thermo Fisher Scientific, Inc.), $10 \mathrm{mM}$ sodium $\beta$-glycerophosphate (Santa Cruz Biotechnology, Inc., Dallas, TX, USA), $100 \mathrm{nM}$ dexamethasone (MP Biomedicals, LLC, Santa Ana, CA, USA) and $50 \mu \mathrm{g} / 1$ ascorbic acid-2-phosphate (Wako Pure Chemical Industries, Ltd., Osaka, Japan).

Adipogenic differentiation. Cells were seeded at a density of 5,000 cells $/ \mathrm{cm}^{2}$ in 6 -well plates and were induced to differentiate the next day. The medium consisted of H-DMEM containing 10\% FBS (both Gibco; Thermo Fisher Scientific, Inc.), $200 \mathrm{mM}$ indomethacin (Sigma-Aldrich; Merck KGaA, Darmstadt, Germany), 0.5 mM isobutyl methylxanthine, $1 \mathrm{mM}$ dexamethasone and $10 \mathrm{mg} / \mathrm{ml}$ insulin (both MP Biomedicals, LLC). The medium was replaced every 3 days.

Chondrogenic differentiation. Approximately 300,000 cells were collected in a $15-\mathrm{ml}$ centrifuge tube and were centrifuged at $300 \mathrm{x} \mathrm{g}$ at room temperature for $5 \mathrm{~min}$. Subsequently, cells were resuspended in $450 \mu \mathrm{l}$ medium consisting of H-DMEM, $1 \mathrm{X}$ insulin-transferrin-selenium-sodium pyruvate (both Gibco; Thermo Fisher Scientific, Inc.), 100 nM dexamethasone (MP Biomedicals, LLC), $50 \mathrm{mM}$ ascorbic acid, $40 \mathrm{mg} / \mathrm{ml}$ proline (both Sigma-Aldrich; Merck KGaA) and $10 \mathrm{ng} / \mathrm{ml}$ transforming growth factor- $\beta 1$ (PeproTech, Inc., Rocky Hill, NJ, USA) . After a 10 min centrifugation at $450 \mathrm{x} g$ at room temperature, the cells were incubated at $37^{\circ} \mathrm{C}$ in an atmosphere containing $5 \% \mathrm{CO}_{2}$.

Evaluation of osteogenic, adipogenic, and chondrogenic differentiation. After a 4-week osteogenic induction, the 
Table I. Antibodies used in flow cytometry.

\begin{tabular}{lcc}
\hline Antibody & Dilution & Supplier \\
\hline $\begin{array}{l}\text { Peridinin chlorophyll protein-Cy5.5-conjugated } \\
\text { anti-human CD105 }\end{array}$ & $1: 20$ & BD Biosciences $^{\mathrm{a}}$ \\
Allophycocyanin-conjugated anti-human CD73 & $1: 20$ & BD Biosciences \\
Fluorescein isothiocyanate-conjugated anti-human & $1: 20$ & BD Biosciences \\
CD90 & & BD Biosciences \\
Phycoerythrin-conjugated anti-human CD44 & $1: 20$ & BD Biosciences \\
Phycoerythrin-conjugated anti-human CD45/CD34 & $1: 20$ & BD Biosciences \\
Phycoerythrin-conjugated anti-human CD45/CD34 & $1: 20$ & \\
CD11b/CD19/HLA-DR isotype control & &
\end{tabular}

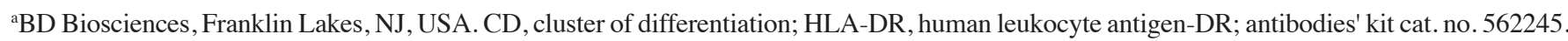

cells were washed with PBS and were fixed with $4 \%$ paraformaldehyde at room temperature for $10 \mathrm{~min}$. Subsequently, cells were stained with fresh $0.1 \%$ Alizarin Red S solution for $30 \mathrm{~min}$ at $37^{\circ} \mathrm{C}$ and examined under an inverted phase contrast microscope (Axiovert 40; Carl Zeiss AG, Oberkochen, Germany).

Adipogenesis was assessed by Oil Red O staining after 4 weeks of induction. The cells were washed and fixed as aforementioned. Subsequently, 0.3\% Oil Red O solution was used to stain the cells for 150-180 sec. The cells were then examined under an inverted phase contrast microscope (Axiovert 40; Carl Zeiss AG).

Histological staining was employed to assess chondrogenic differentiation after a 3 -week induction. Cartilage nodules formed by the cells were fixed with $4 \%$ paraformaldehyde at $4^{\circ} \mathrm{C}$ overnight and were then embedded in paraffin. The blocks were cut into $5 \mu \mathrm{m}$ sections. The expression levels of collagen type II were then detected. Sections were incubated with rabbit anti-human collagen type II antibodies (Sigma-Aldrich; dilution, 1:80; cat. no. SAB4500366) in blocking buffer (10\% goat serum sealant, cat. no. SL038; Solarbio, Beijing, China) for $16 \mathrm{~h}$ at $4^{\circ} \mathrm{C}$. Biotinylated goat anti-rabbit immunoglobulin G (cat. no. SA1022; Wuhan Boster Biological Technology, Ltd., Wuhan, China) was used as a secondary antibody incubating at $37^{\circ} \mathrm{C}$ for $30 \mathrm{~min}$ and was detected using streptavidin-biotin complex reagent (cat. no. SA1022; Wuhan Boster Biological Technology, Ltd.). The staining was visualized with 3,3'-diaminobenzidine (cat. no. AR1022; Wuhan Boster Biological Technology, Ltd.) and was observed under a light microscope (Axioskop 40; Carl Zeiss AG). Sections incubated without the primary antibody served as a control.

Sulfated glycosaminoglycan (GAG) assays were performed to determine the levels of GAG. Chondrogenic nodules were digested overnight at $56^{\circ} \mathrm{C}$ in $50 \mu \mathrm{g} / \mathrm{ml}$ proteinase $\mathrm{K}$ solution Santa Cruz Biotechnology, Inc.) diluted in $100 \mathrm{mM} \mathrm{Na}_{2} \mathrm{HPO}_{4}$ ( $\mathrm{pH} \mathrm{8.0),} \mathrm{followed} \mathrm{by} \mathrm{inactivation} \mathrm{for} 10 \mathrm{~min}$ at $90^{\circ} \mathrm{C}$. After centrifugation, $500 \mu \mathrm{l}$ working 1,9-dimethylmethylene blue (DMMB) solution (Santa Cruz Biotechnology, Inc.; $100 \mathrm{ml} \mathrm{1M} \mathrm{GuHCl,} 1 \mathrm{~g}$ sodium formate, $1 \mathrm{ml} \mathrm{98 \%} \mathrm{formic}$ acid, $25 \mathrm{ml} 0.64 \%$ DMMB ethanol solution completed to $500 \mathrm{ml}$ with distilled water was defined as solution A; $100 \mathrm{ml}$ $1 \mathrm{M} \mathrm{GuHCl}, 1 \mathrm{~g}$ sodium formate, $1 \mathrm{ml} \mathrm{98 \%} \mathrm{formic} \mathrm{acid,} 25 \mathrm{ml}$
$100 \%$ ethanol completed to $500 \mathrm{ml}$ with distilled water was defined as solution B; working DMMB solution was made by rapidly mixing solution $\mathrm{A}$ with solution $\mathrm{B}$ ) was added to $50 \mu \mathrm{l}$ treated sample or standard sample. Subsequently, the samples were mixed vigorously for $30 \mathrm{~min}$ and centrifuged for $10 \mathrm{~min}$ at $12,000 \times \mathrm{g}$ at $4^{\circ} \mathrm{C}$. Once the supernatant was discarded, $1 \mathrm{ml}$ DMMB decomplexation solution [50 mM sodium acetate (pH 6.8) added with $10 \%$ methyl alcohol, 4M GuHCl] was added. After a further $30 \mathrm{~min}$ of agitation, absorbance was examined at $656 \mathrm{~nm}$ using a microplate reader (Infinite 200; Tecan Group, Ltd.). Double-stranded DNA, which was obtained from the chondrogenic nodules digestion fluid, as detected by Quant-iT PicoGreen dsDNA reagent (Invitrogen; Thermo Fisher Scientific, Inc.), was used as an endogenous control.

Hematoxylin and eosin (HE) staining of SF and SSS sections and histological immunostaining of SSS sections. Sections were stained with Mayer's hematoxylin for $15 \mathrm{~min}$ and with eosin for $1 \mathrm{~min}$. After gradient dehydration and clearing, the sections were mounted and observed under a light microscope (Axioskop 40; Carl Zeiss AG). Histological immunostaining of SSS sections was performed in the same manner as mentioned above. Mouse anti-human CD105 antibody (cat. no. ab11414; dilution, 1:200; Abcam, Cambridge, UK) was used as the primary antibody and biotinylated goat anti-mouae immunoglobulin G (cat. no. A1001; Wuhan Boster Biological Technology, Ltd.) was used as the secondary antibody.

Evaluation of gene expression by reverse transcription-quantitative polymerase chain reaction (RT-qPCR). Total RNA was extracted from cells using TRIzol reagent (Invitrogen: Thermo Fisher Scientific, Inc.) and cDNA was synthesized using a Transcriptor First Strand cDNA Synthesis kit (Roche Diagnostics, Basel, Switzerland) according to the manufacturers' protocols. qPCR analyses were performed using a LightCycler ${ }^{\circledR} 480$ Probes Master system (Roche Diagnostics) with an initial denaturation at $95^{\circ} \mathrm{C}$ for $10 \mathrm{~min}$, followed by 40 cycles of $95^{\circ} \mathrm{C}$ for $15 \mathrm{sec}$ and $60^{\circ} \mathrm{C}$ for $60 \mathrm{sec}$. A melting curve analysis was then performed. GAPDH was used as an internal control. Relative mRNA expression levels were evaluated using the following formula: $\left(\mathrm{Cq}_{\text {target gene }}-\mathrm{Cq}_{\text {gapdh }}\right)$ 

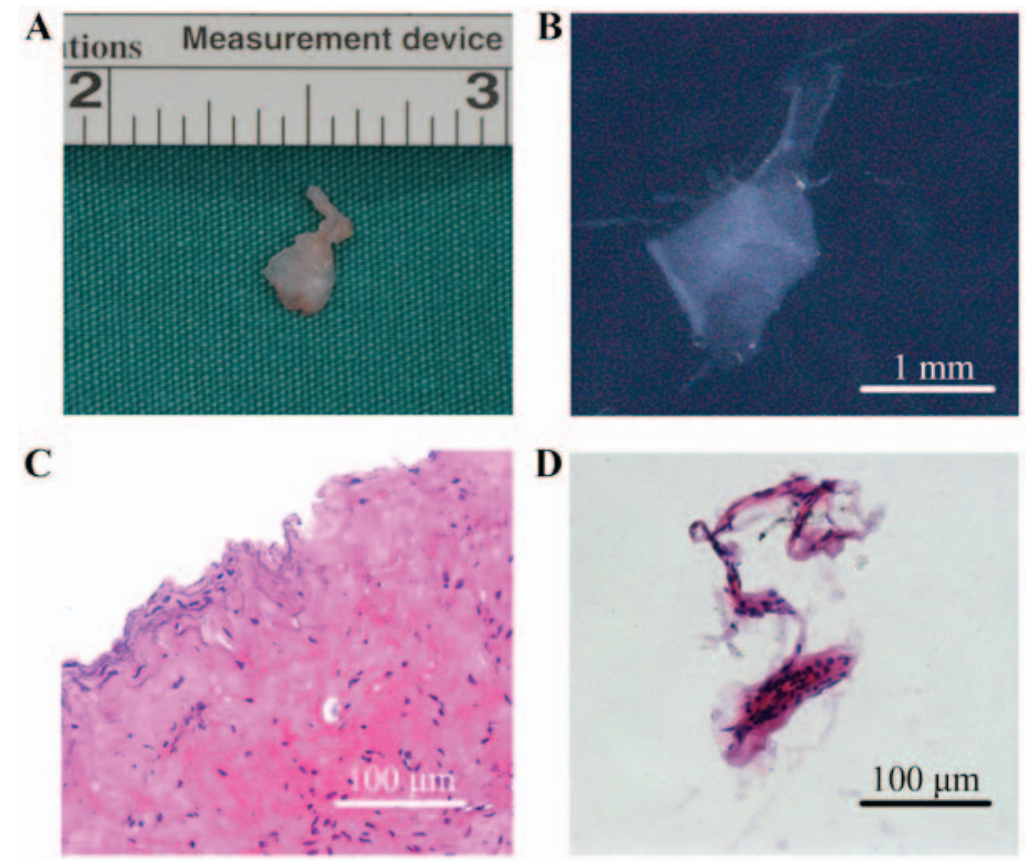

Figure 1. Characteristics of SFs and SSSs collected from patients with temporomandibular joint osteoarthrosis. (A) Gross morphology of SSSs; (B) gross morphology of SFs; (C) HE-stained histological section of SSSs; (D) HE-stained histological section of SFs. HE, hematoxylin and eosin; SFs, synovial fragments; SSSs, surgery-obtained synovium specimens.

Table II. Oligonucleotide primers used in quantitative polymerase chain reaction.

\begin{tabular}{ll}
\hline Gene & \multicolumn{1}{c}{ Primer sequence (5'-3') } \\
\hline GAPDH & F: GACAGTCAGCCGCATCTTCT \\
& R: TTAAAAGCAGCCCTGGTGAC \\
$R U N X-2$ & F: TCAACGATCTGAGATTGTGGG \\
& R: GGGGAGGATTTGGAAGACGG \\
OCN & F: CCACCGAGACACCATGAGAG \\
& R: TCAGCCAACTCGTCACAGTC \\
ALP & F: ACCATTCCCACGTCTTCACATTTG \\
& R: AGACATTCTCTCGTTCACCGCC \\
$P P A R G 2$ & F: GCAAACCCCATTCCATGCTG \\
& R: CACGGAGCTGATCCCAAAGT \\
LPL & F: CAAGAGTGAGTGACAAC \\
& R: AATTATGCTGAAGGACAAC \\
$S O X-9$ & F: ACACACAGCTCACTCGACCTTG \\
& R: AGGGAATCTGGTTGGTCCTCT \\
& F: GGCAATAGCAGGTTCACGTACA \\
& R: CGATAACAGTCTTGCCCCACTT
\end{tabular}

$A L P$, alkaline phosphatase; $C O L-2$, type II collagen; F, forward; $L P L$, lipoprotein lipase; $O C N$, osteocalcin; ; $P P A R G 2$, peroxisome proliferator-activated receptor $\gamma$, transcript variant 2; R, reverse; $R U N X-2$, runt-related transcription factor 2; SOX-9, sex-determining region Y-box 9.

sample $-\left(\mathrm{Cq}_{\text {target gene }}-\mathrm{Cq}_{\text {gapdh }}\right)_{\text {control }}$ (23).PCR primer sequences are listed in Table II.

Statistical analysis. Data were statistically analysed using SPSS 10.0 software (SPSS, Inc., Chicago, IL, USA). Experiments were repeated at least 3 times and numerical data are presented as the mean \pm standard deviation. Student's t-test was used to analyze results for 2 independent groups. Comparisons between multiple groups were conducted using one-way analysis of variance (ANOVA) followed by Bonferroni's post hoc test. $\mathrm{P}<0.05$ was considered to indicate a statistically significant difference.

\section{Results}

Characterization of SFs, SSSs, SFCs and SSSCs expanded in vitro. The SFs collected from patients with TMJ osteoarthrosis were membranous and translucent, whereas SSSs were masses of tissue (Fig. 1A and B). HE staining revealed that SSSs exhibited a more complex histological structure, containing intima and subintima (Fig. 1C), whereas the SFs were formed of several layers of cells only, indicating that they were obtained from the intima (Fig. 1D).

Adherent cells were obtained from SFs and SSSs. The SFCs and SSSCs both exhibited a typical fibroblastic spindle shape (Fig. 2A and B). In addition, both cell types exhibited clone-forming potential (Fig. 2C and D). The clone-forming rate of SFCs was slightly lower than that of SSSCs (Fig. 2E; P=0.014).

Cell proliferation curves demonstrated that SFCs exhibited a growth pattern similar to that of SSSCs (Fig. 2F). The PD and DT of SFCs were $2.58 \pm 1.01$ and $30.73 \pm 5.90 \mathrm{~h}$, respectively, whereas the PD and DT of SSSCs were $3.18 \pm 1.38$ and $24.88 \pm 5.07 \mathrm{~h}$, respectively, at passage 4 .

Surface marker assays for SFCs and SSSCs. The results of a flow cytometric analysis indicated that $>95 \%$ of SFCs derived from all $3 \mathrm{SFs}$ expressed positive markers of MSCs, including CD90, CD44, CD73 and CD105. Negative markers of MSCs: CD11b, CD19, CD34, CD45 and human leukocyte antigen (HLA)-DR, were positive in $<2 \%$ of cells (Fig. 3). In addition, 

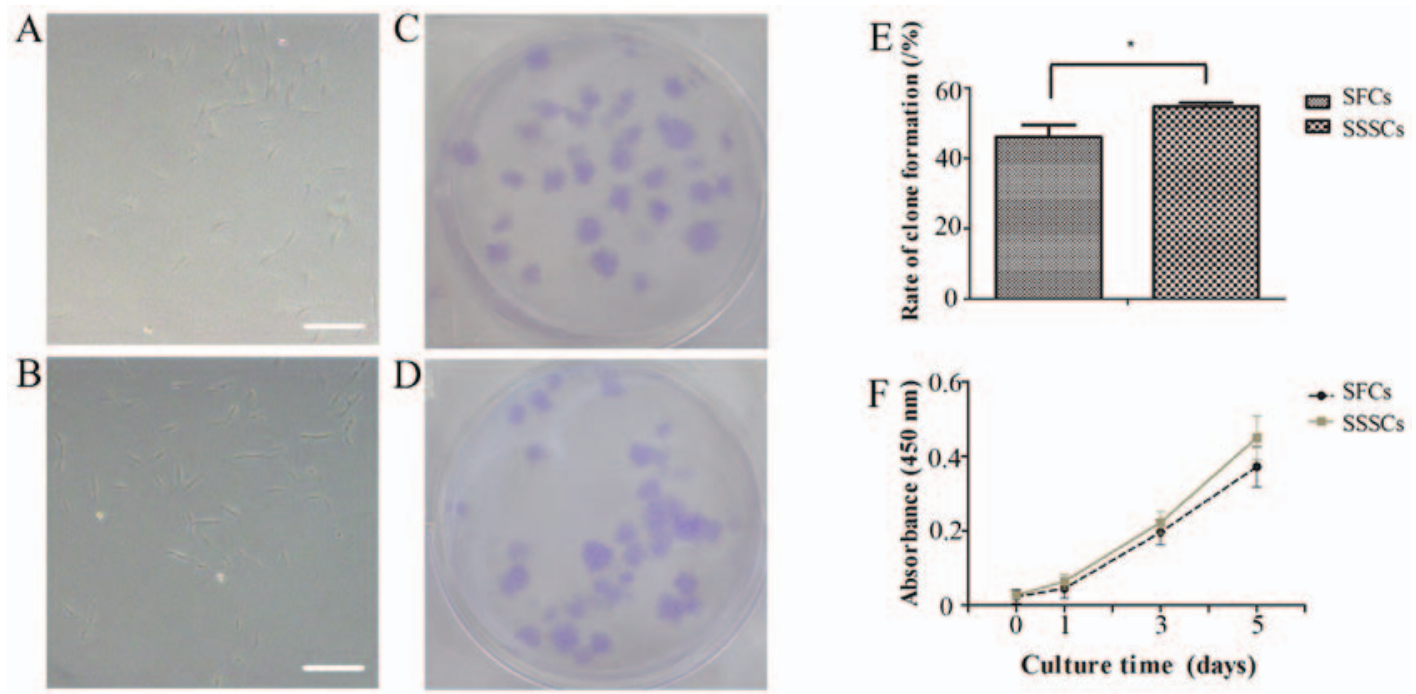

Figure 2. Clone-forming and proliferation assays for SFCs and SSSCs. Typical morphology of (A) SFCs and (B) SSSCs expanded in vitro. Scale bars, $100 \mu \mathrm{m}$. Clone formation of (C) SFCs and (D) SSSCs after 14 days of culture. (E) Clone-forming rates of SFCs and SSSCs after culturing in vitro for 2 weeks.

(F) Cell growth curves for SFCs and SSSCs. " $\mathrm{P}<0.05$. SFCs, synovial fragment cells; SSSCs, surgery-obtained synovium specimen cells.
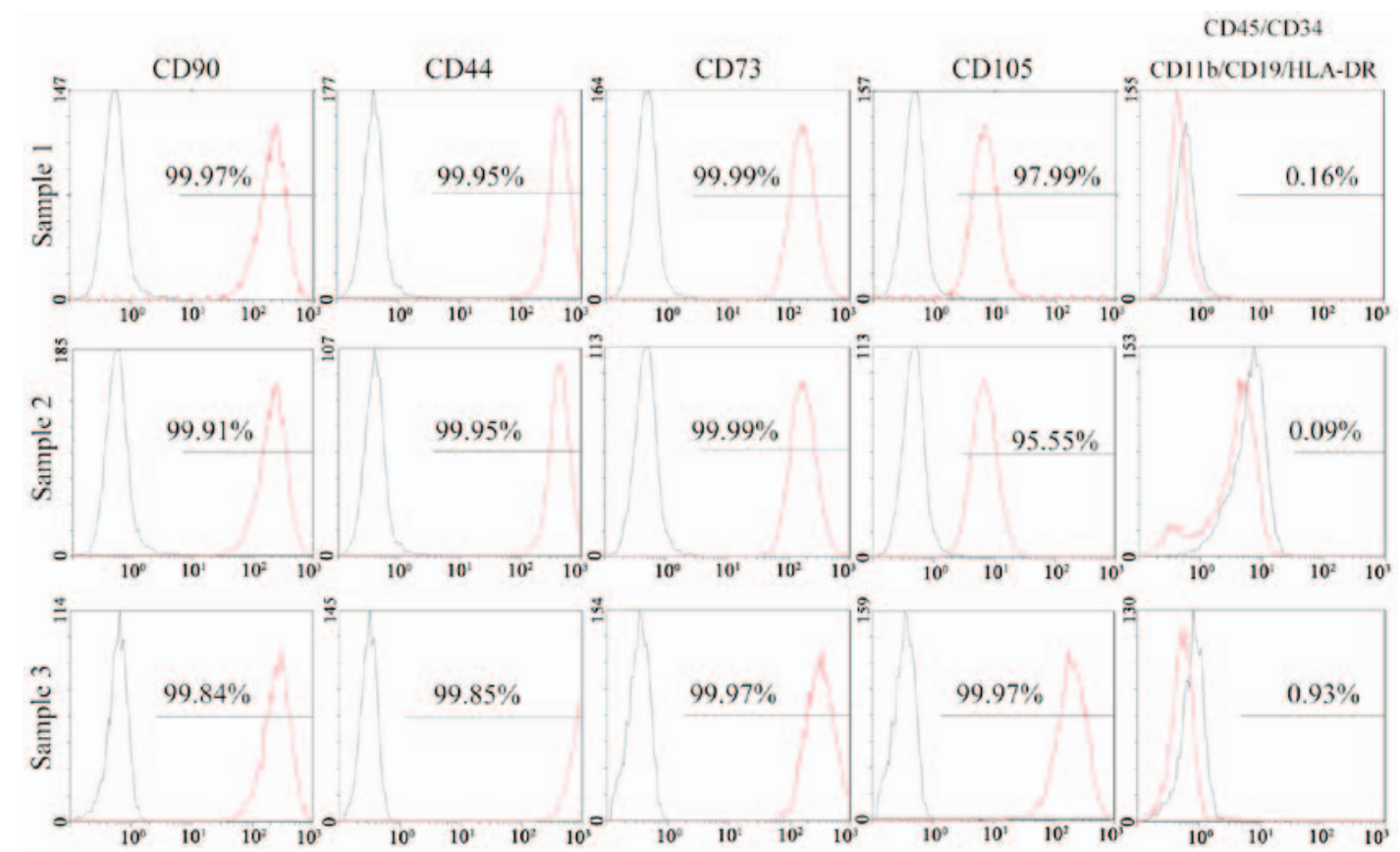

Figure 3. Flow cytometric analysis of SF cells derived from $3 \mathrm{SFs}$. The black lines represent negative controls and the red lines represent experimental groups. $\mathrm{CD}$, cluster of differentiation; HLA-DR, human leukocyte antigen-DR; SF, synovial fragment.

95\% of SSSCs derived from all 6 SSSs expressed CD90, CD44 and CD73. However, the percentage of $\mathrm{CD} 105^{+}$cells in two of the SSSs was much lower (32.36 and 74.08\%), whereas that in the other four samples was $>95 \%$. Negative markers of MSCs were expressed in $>2 \%$ of cells for 3 SSSs (Fig. 4). The results of immunohistochemical staining demonstrated that $\mathrm{CD} 05^{+}$ cells were located in the intima and subintima, indicating that CD105 was not a specific marker for SMSCs (Fig. 5).

\section{Differentiation potential of SFCs and SSSCs.}

Osteogenic differentiation. Calcium deposits were detected in both groups after a 4-week osteogenic induction, as confirmed by Alizarin Red S staining (Fig. 6A-L). The expression levels of osteogenesis-associated genes, including runt-related transcription factor 2 (Fig. 6M), osteocalcin (Fig. 6N) and alkaline phosphatase (Fig. 6O), were significantly upregulated in induced SFCs and SSSCs compared with those in the corresponding control groups. However, there were no differences between the two induced groups. Results are presented in Table III.

Adipogenic differentiation. Oil red O-positive, lipid-laden fat cells were detected in SFCs and SSSCs after a 4-week adipogenic induction (Fig. 7A-F). In addition, the expression levels of peroxisome proliferator-activated receptor $\gamma$, transcript variant 2 (Fig. 7G) and lipoprotein lipase (Fig. 7H) were significantly upregulated in both induced cell types compared with in the control groups. No differences were detected 

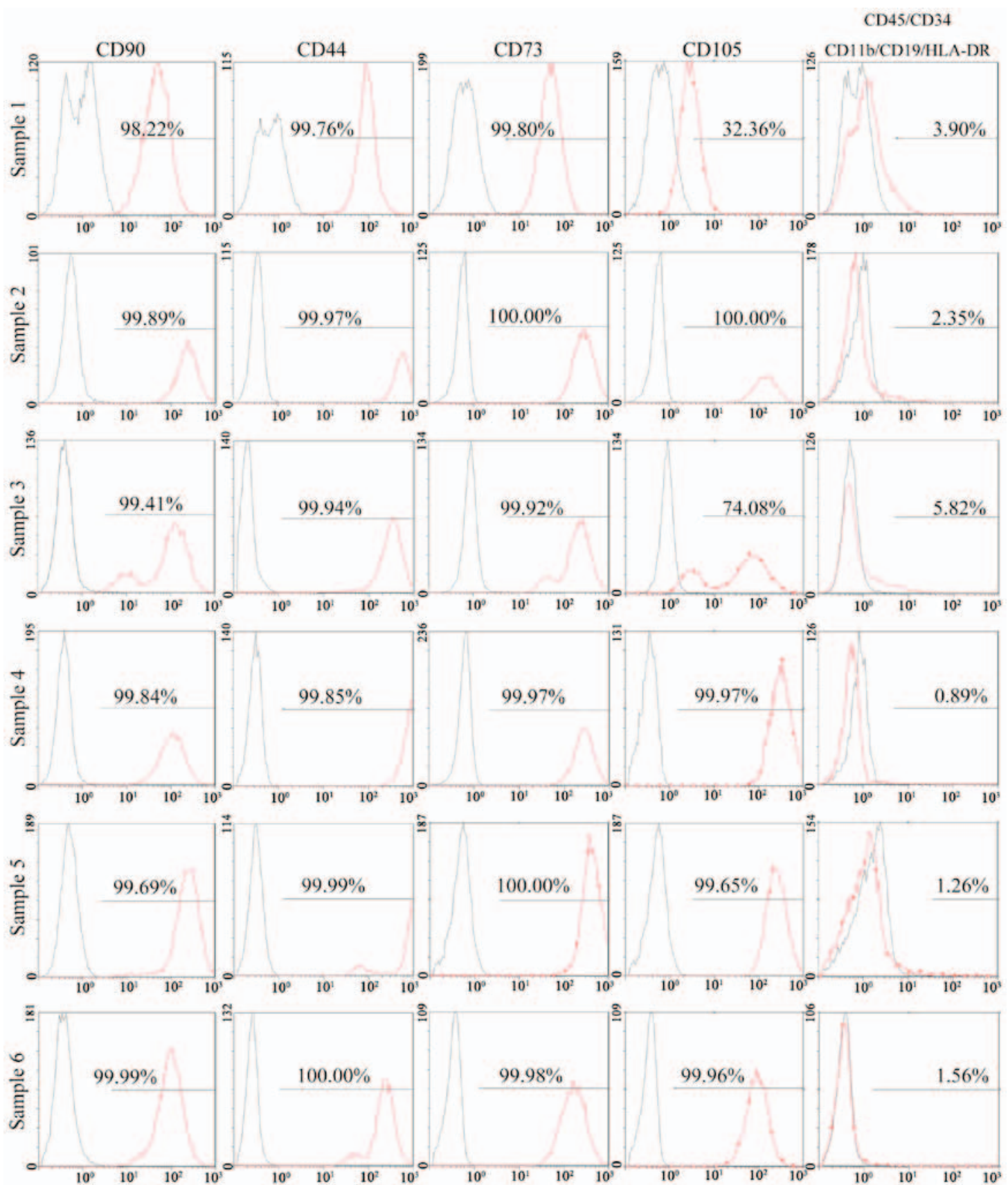

Figure 4. Flow cytometric analysis of SSS cells derived from 6 SSSs. The black lines represent negative controls and the red lines represent experimental groups. CD, cluster of differentiation; HLA-DR, human leukocyte antigen-DR; SSS, surgery-obtained synovium specimen.

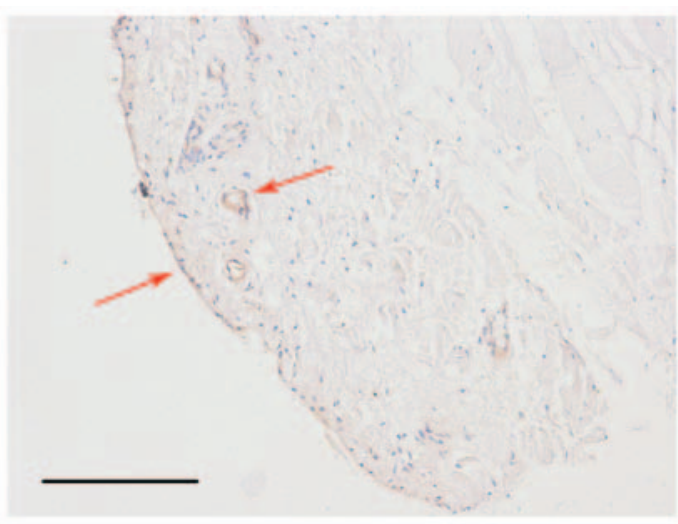

Figure 5. Immunohistochemical analysis of cluster of differentiation 105 in surgery-obtained synovium specimens. Scale bar, $100 \mu \mathrm{m}$. between the two induced groups. Results are presented in Table III.

Chondrogenic differentiation. Chondrogenic differentiation was assessed by detection of cartilage nodules and collagen type II expression (Fig. 8). Cartilage nodules were formed by SFCs (Fig. 8A, E and I) and SSSCs (Fig. 8C, $\mathrm{G}$ and $\mathrm{K}$ ) after a 3 -week chondrogenic induction. In addition, collagen type II expression was detected in cartilage nodule sections formed by SFCs (Fig. 8B, F and J) and SSSCs (Fig. 8D, $\mathrm{H}$ and $\mathrm{L}$ ), as confirmed by immunohistochemical staining. Immunofluorescence staining was also conducted on cells without induction, which served as the control group; however, no immunostaining was detected (data not shown). In addition, the mRNA expression levels of sex-determining region 

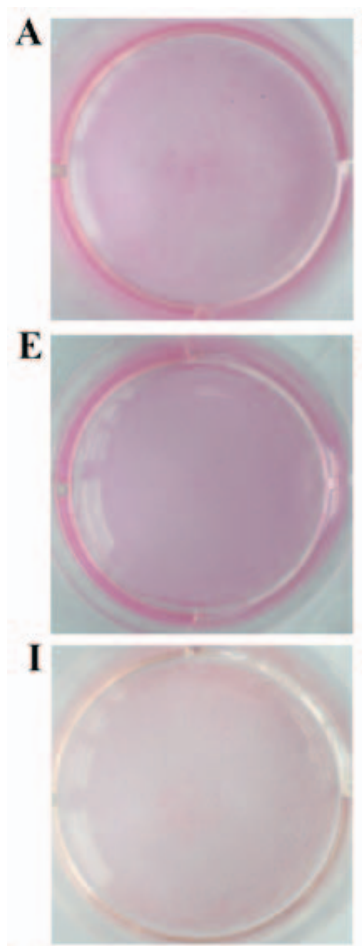

M

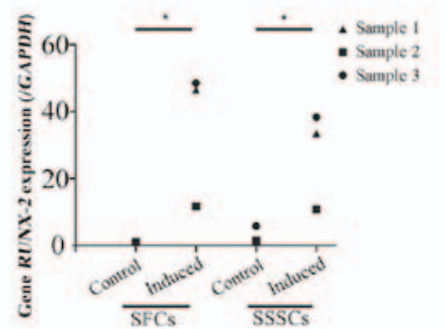

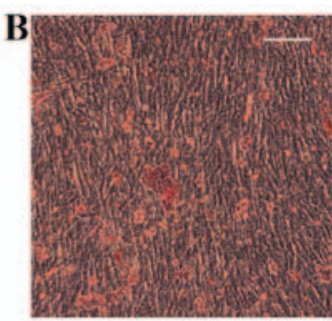
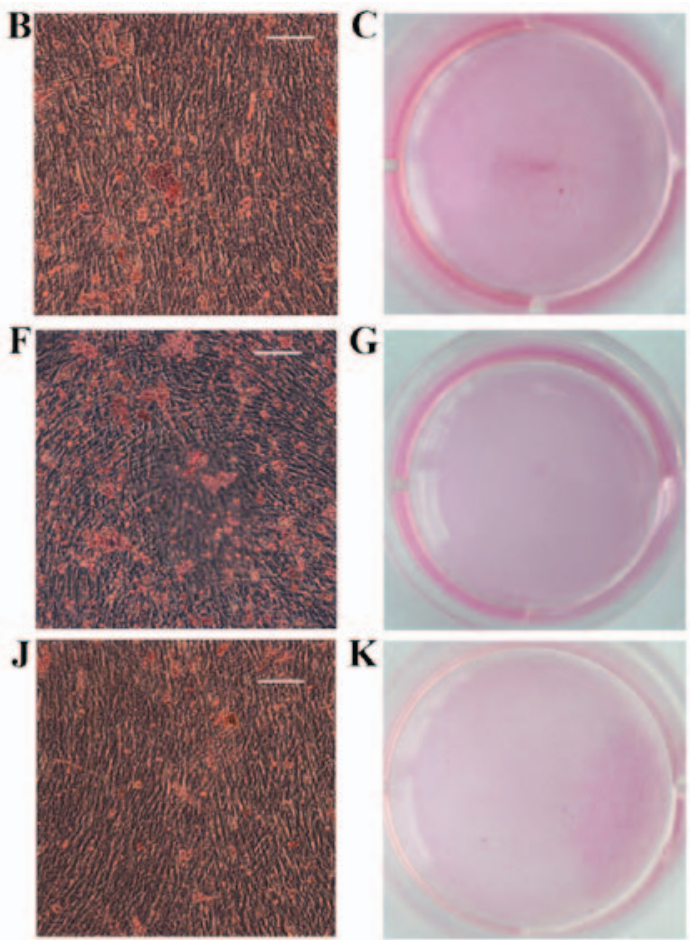

$\mathbf{N}$
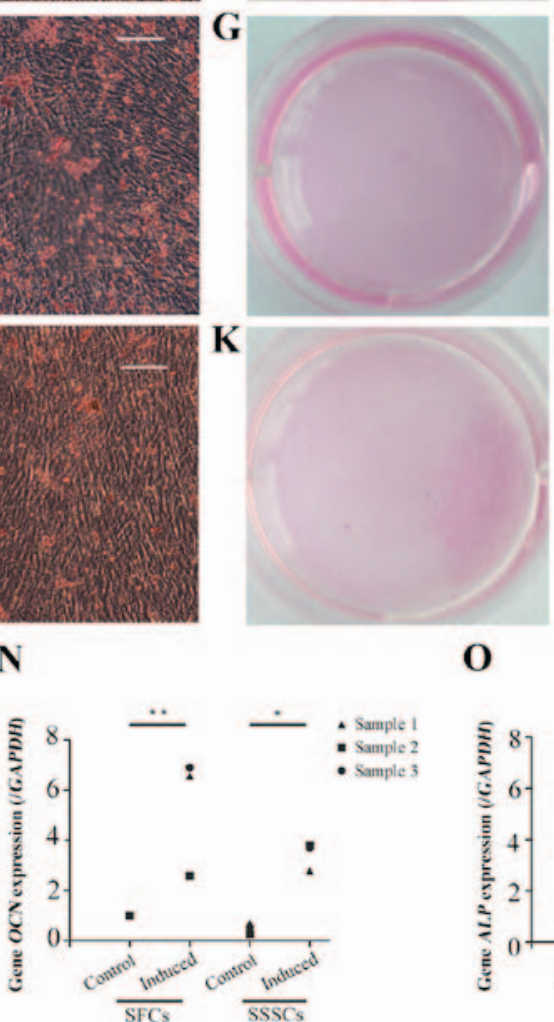

o
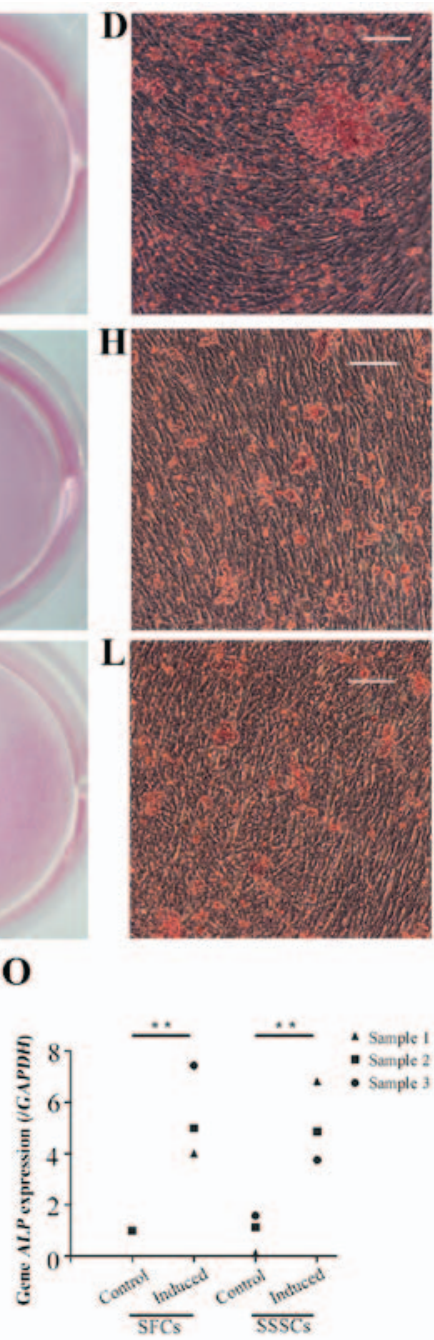

Figure 6. Osteogenic differentiation of SFCs and SSSCs. Calcium deposits were confirmed by Alizarin Red S staining in (A, B, E, F, I and J) SFCs and (C, D, $\mathrm{G}, \mathrm{H}, \mathrm{K}$ and L) SSSCs. Scale bars, $100 \mu \mathrm{m}$. qPCR results for (M) RUNX-2, (N) $O C N$, and (O) $A L P$ expression in SFCs and SSSCs compared with those in the corresponding control groups. ${ }^{*} \mathrm{P}<0.05,{ }^{* *} \mathrm{P}<0.01$. ALP, alkaline phosphatase; $O C N$, osteocalcin; $R U N X-2$, runt-related transcription factor 2 ; SFCs, synovial fragment cells; SSSCs, surgery-obtained synovium specimen cells.

Table III. Expression after multipotent differentiation.

P-values

Genes and

SFCs-control SSSCs-control SFCs-induced

proteins SFCs-control SFCs-induced SSSCs-control SSSCs-induced SFCs-induced SSSCs-induced SSSCs-induced

\begin{tabular}{lccccccc}
\hline RUNX-2 & $1.00 \pm 0.00$ & $35.61 \pm 20.77$ & $2.92 \pm 2.50$ & $27.58 \pm 14.68$ & 0.01 & 0.05 & 0.46 \\
OCN & $1.00 \pm 0.00$ & $5.35 \pm 2.41$ & $0.50 \pm 0.23$ & $3.43 \pm 0.56$ & 0.003 & 0.02 & 0.10 \\
ALP & $1.00 \pm 0.00$ & $5.49 \pm 1.76$ & $0.94 \pm 0.75$ & $5.15 \pm 1.56$ & 0.002 & 0.003 & 0.75 \\
PPARG2 & $1.00 \pm 0.00$ & $46.56 \pm 22.84$ & $1.59 \pm 0.93$ & $49.65 \pm 12.59$ & 0.003 & 0.002 & 0.78 \\
LPL & $1.00 \pm 0.00$ & $741.14 \pm 284.52$ & $5.42 \pm 7.80$ & $705.91 \pm 320.99$ & 0.003 & 0.004 & 0.85 \\
SOX-9 & $1.00 \pm 0.00$ & $1.53 \pm 0.31$ & $0.76 \pm 0.42$ & $1.84 \pm 0.04$ & 0.04 & 0.001 & 0.18 \\
COL-2 & $1.00 \pm 0.00$ & $6.00 \pm 0.82$ & $0.88 \pm 0.15$ & $6.58 \pm 0.31$ & $<0.001$ & $<0.001$ & 0.15 \\
GAG & $1.36 \pm 0.06$ & $7.61 \pm 0.55$ & $1.36 \pm 0.06$ & $8.07 \pm 1.81$ & $<0.001$ & $<0.001$ & 0.57 \\
\hline
\end{tabular}

$A L P$, alkaline phosphatase; $C O L-2$, type II collagen; GAG, glycosaminoglycan; $L P L$, lipoprotein lipase; $O C N$, osteocalcin; $P P A R G 2$, peroxisome proliferator-activated receptor $\gamma$, transcript variant 2; RUNX-2, runt-related transcription factor 2; SFCs, synovial fragment cells; SOX-9, sex-determining region Y-box 9; SSSCs, surgery-obtained synovium specimen cells. 
Table IV. Main differences between SFCs and SSSCs.

$\begin{array}{lll}\text { Properties } & \text { SFCs } & \text { SSSCs }\end{array}$

Source of separated MSCs

Markers of MSC expression

in primary cells

Ethical controversy
Only from the intima (synovium)

Higher uniformity

Less
Intima (synovium) and subintima, including MSCs from pericytes

Less uniformity

SFCs, spinal fragment cells; SSSCs, surgery-obtained synovium specimen cells; MSCs, mesenchymal stem cells.
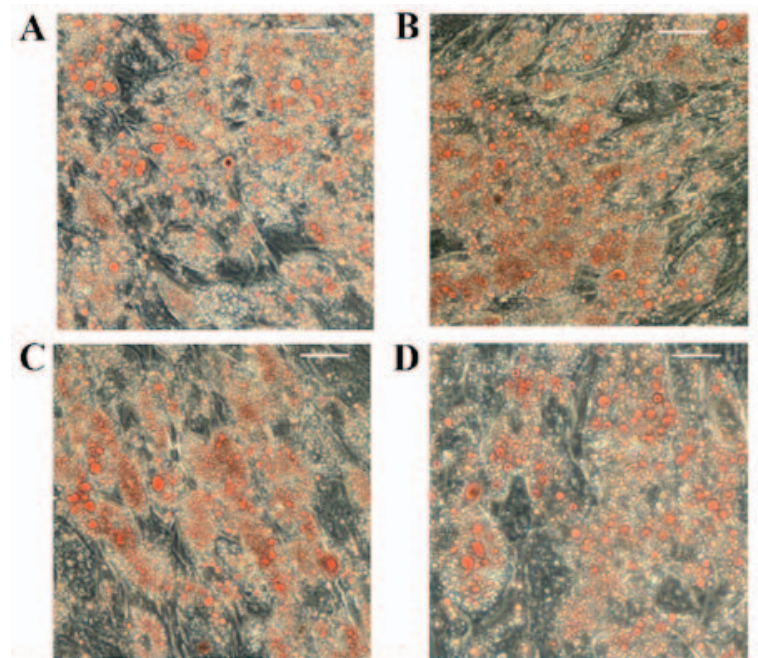

E

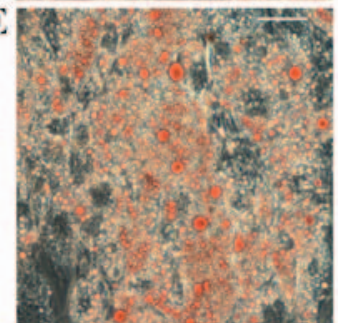

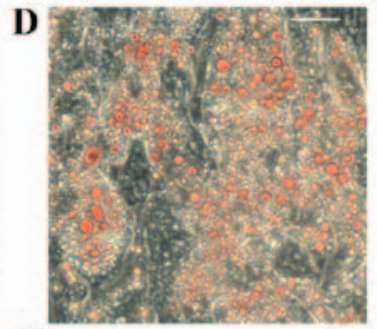

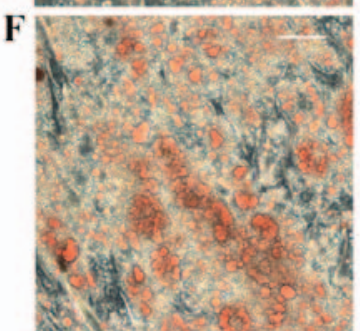

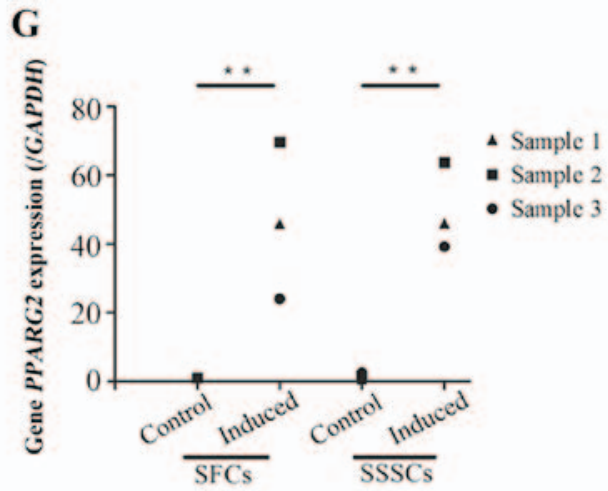

H

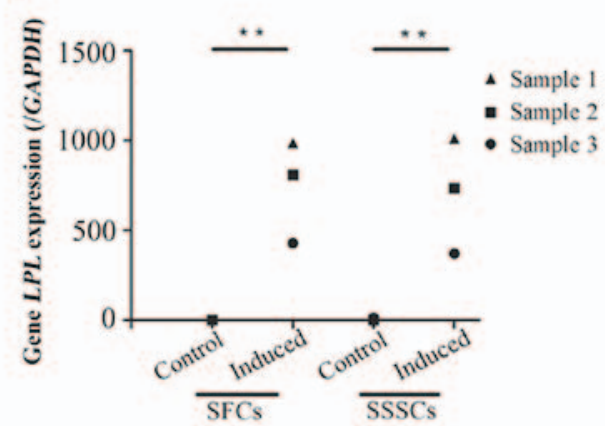

Figure 7. Adipogenic differentiation of SFCs and SSSCs. Oil red O staining of (A, C and E) SFCs and (B, D and F) SSSCs after induction for 4 weeks. Scale bars, $100 \mu \mathrm{m}$. qPCR results for (G) PPARG2 and (H) LPL expression in SFCs and SSSCs compared with in the corresponding control groups. ${ }^{* * *} \mathrm{P}<0.01$. $L P L$, lipoprotein lipase; PPARG2, peroxisome proliferator-activated receptor $\gamma$, transcript variant 2; SFCs, synovial fragment cells; SSSCs, surgery-obtained synovium specimen cells.

Y-box 9 (Fig. 8M) and type II collagen (Fig. 8N), and the production of GAG (Fig. 8O) were significantly upregulated in both cell types compared with in the control groups. No differences were detected between the two induced groups. Results are presented in Table III.

\section{Discussion}

The present study investigated the morphological characteristics of cells derived from SFs and SSSs. The main differences between SFCs and SSSCs are summarized in Table IV. The main similarities between the cell types were as follows: i) Positive expression of typical markers of MSCs, including CD44, CD73, CD90 and CD105, and negative expression of CD34, CD45, CD79 $\alpha /$ CD19, CD14/CD11b and HLA-DR; ii) fibroblast-like and spindle-shaped morphology; iii) multi-lineage differentiation potential; and iv) clone-forming potential.
These cells exhibited similar morphological characteristics, and no significant differences in osteogenic, adipogenic or chondrogenic differentiation potential.

After the initial characterization of bone marrow stromal cells in the late 1960s, the concept of MSCs was established, and progenitor cells with similar properties have been isolated from various sources (24). In 2006, the International Society for Cellular Therapy (ISCT) set criteria for the definition of MSCs, defining MSCs as cells with the ability to adhere to plastic in standard culture conditions and to differentiate into osteogenic, adipogenic and chondrogenic lineages. Furthermore, according to the ISCT criteria, $>95 \%$ of cells must express CD90, CD105 and CD73, whereas <2\% of cells should express CD34, CD45, CD79 $\alpha / C D 19$, CD14/CD11b and HLA-DR (14). In the present study, all 3 SFC samples met these criteria. Conversely, in 3 out of 6 SSS samples, the percentage of SSSCs that expressed negative markers was 

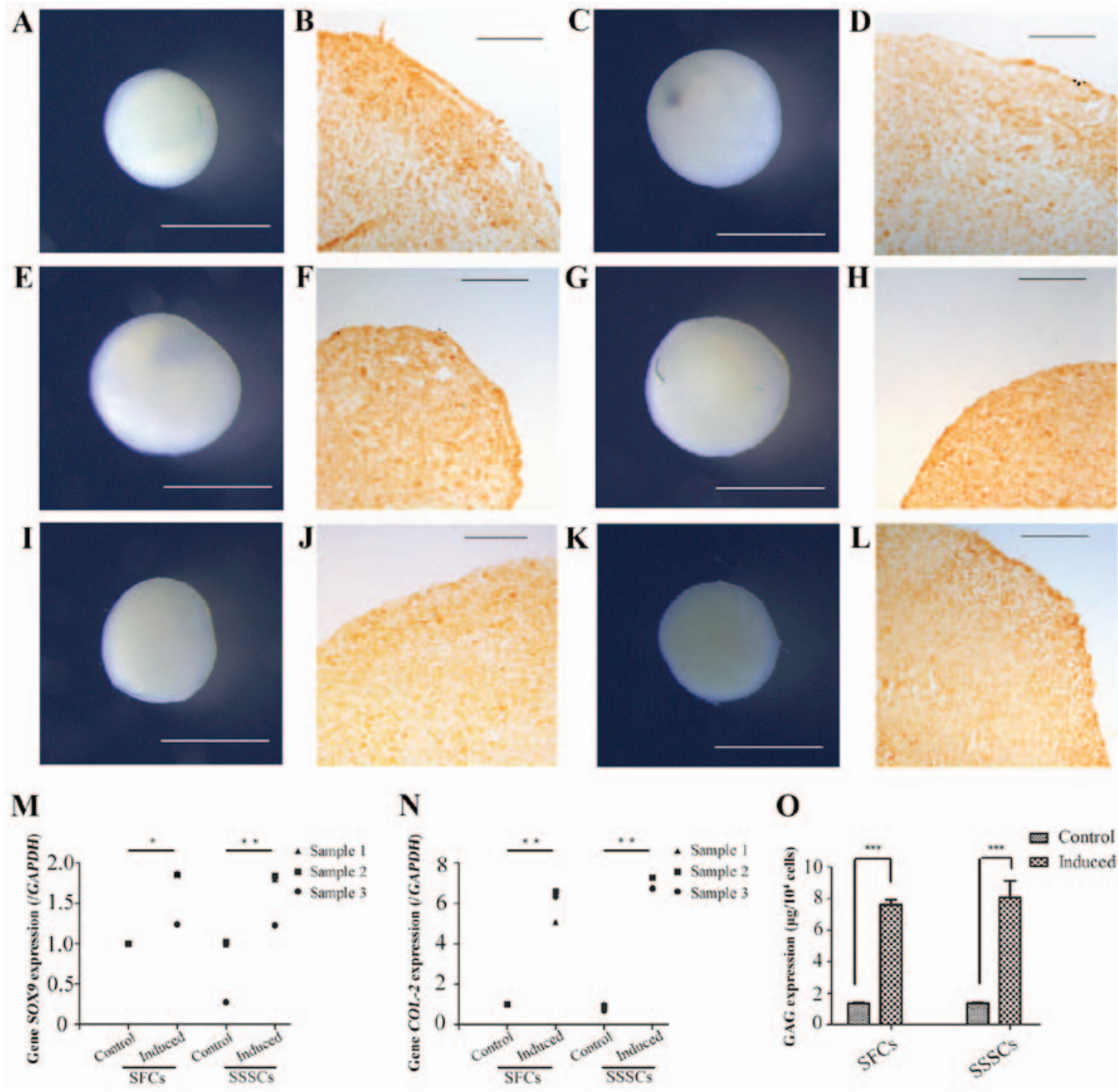

Figure 8. Chondrogenic differentiation of SFCs and SSSCs. Gross morphology of cartilage nodules formed by (A, E and I) SFCs and (C, G and K) SSSCs. Immunohistochemical staining of type II collagen in the cartilage nodules formed by (B, F and J) SFCs and (D, H and L) SSSCs. Scale bars, (B, D, F, H, $\mathrm{J}$ and L) $100 \mu \mathrm{m}$ and (A, C, E, G, I and K) $1 \mathrm{~mm}$. qPCR results for (M) SOX-9 and (N) COL-2 expression in SFCs and SSSCs compared with in the corresponding control groups. (O) GAG levels in cartilage nodules formed by SFCs and SSSCs. ${ }^{*} \mathrm{P}<0.05,{ }^{* *} \mathrm{P}<0.01$ and ${ }^{* * * *} \mathrm{P}<0.001$. COL-2, type II collagen; GAG, glycosaminoglycan; SFCs, synovial fragment cells; SOX-9, sex-determining region Y-box 9; SSSCs, surgery-obtained synovium specimen cells.

$>2 \%$. Furthermore, in 2 out of 6 SSS samples, the percentage of SSSCs that expressed CD105 was $<95 \%$.

Synovium samples obtained through arthroscopic or surgical procedures consist of two layers: The intima (synovial membrane) and subintima. The intima consists of several cell layers, whereas the subintima consists of various cells lying over loose connective tissue, alongside matrix proteins, fibroblasts, macrophages, lymphocytes, blood vessels and MSCs (25-29). MSCs are present in various areas of the joint, including the intima and subintima (30-32). Since there is no effective method for the separation of the intima and subintima, the SSMSCs reported previously were not only from the synovium (intima), but also from the subintima. Therefore, MSCs specifically from the intima (SMSCs) remain poorly understood.

The present study demonstrated that SFs were present in the synovial fluid obtained from patients with TMJ osteoarthrosis. Shearing forces, natural remodelling and relative tissue weakening from lack of nutrients may contribute to the avulsion of the superficial lining $(32,33)$. SFs consist of several layers of cells only, indicating that this tissue is shed from the intima and may serve as a better source of SMSCs. Furthermore, SFs can be obtained by arthrocentesis, which is a common more acceptable treatment strategy for patients with TMJ osteoarthrosis, as it is less invasive than open surgery. Accordingly, SFs are a patient-friendly source for SMSCs, which may be used in studies regarding TMJ osteoarthrosis.

MSCs can be isolated from synovium samples and are thought to be a promising cell type for cartilage repair due to anatomical position $(34,35)$. Compared with other MSC sources, the synovium is the closest tissue to articular cartilage, and SSSCs exhibit a higher chondrogenic capacity, and can be harvested through routine arthroscopic or surgical procedures $(9,18,36,37)$. The sources of these MSCs are complex and include the intima, subintima and peripheral circulation. Due to vascular recruitment, MSCs located around the blood vessels 
in the subintima may have misled studies regarding the origin of synovial membrane-derived MSCs (SMMSCs) $(20,38,39) . \mathrm{Li}$ and Makarov generated animal models of rheumatoid arthritis and demonstrated that arthritic fibroblast-like synoviocytes contain a substantial ( $>30 \%$ ) fraction of bone marrow-derived precursors that can differentiate into various mesenchymal cell types in vitro (40). Furthermore, the higher chondrogenic capacity of SMMSCs remains poorly understood. The present study indicated that the differentiation potentials of SFCs, including chondrogenic differentiation potential, were not significantly different from those of SSSCs, thus suggesting that the higher chondrogenic capacity of SMMSCs was not determined by MSCs residing in the intima.

No specific markers for SMSCs have been identified to date. Harvanova et al reported that $40-50 \%$ of cells isolated from synovial samples are positive for CD105 (19). CD105 serves as an immunomagnetic separation marker for isolating SMMSC populations (19). The present study also confirmed that CD105- cells were present in the cell population isolated from SSSs, but not that isolated from SFs. However, $\mathrm{CD}_{105^{+}}$cells were present in the intima and subintima, indicating that CD105 was not a specific marker for SMSCs. Since SFs consist of only intima, this tissue may allow for the exploration of markers specific to SMSCs.

In conclusion, the present study isolated MSCs from SFs and demonstrated that these SFCs were similar in morphology, growth and trilineage differentiation potential to SSSCs. However, SFCs exhibited more homogeneous characteristics than SSSCs. Not only were SFCs more uniform than SSSCs in terms of MSC surface marker expression in primary cells, but SFCs derived from SFs also consisted only of intima (synovium), thus exhibiting more homogeneity with regards to cell source. Conversely, SSSCs were derived from SSSs, which consisted of intima and subintima. In addition, the source of separated MSCs from SSSs exhibited heterogeneity, since SSSCs may contain MSCs from pericytes. Unlike other joints, including knee joints, the size of SSSs are limited; therefore, removing excessive synovial specimens from the TMJ raises ethical concerns. However, the process for obtaining SFs is simpler and less invasive, thereby making it more acceptable to patients and more in compliance with ethical and moral standards. Therefore, SFs may serve as an improved cell source for the study of SMSCs. Notably, obtaining MSCs from the intima is a key step in the exploration of specific SMSC markers. In the present study, although SFCs were confirmed as MSCs derived from the intima, specific markers for SMSCs remain to be identified; therefore, our future studies aim to investigate these markers.

\section{Acknowledgements}

The present study was supported by a grant from the National Science Foundation of China (grant no. 81271115).

\section{References}

1. Pittenger MF, Mackay AM, Beck SC, Jaiswal RK, Douglas R, Mosca JD, Moorman MA, Simonetti DW, Craig S and Marshak DR: Multilineage potential of adult human mesenchymal stem cells. Science 284: 143-147, 1999.

2. Jackson WM, Nesti LJ and Tuan RS: Potential therapeutic applications of muscle-derived mesenchymal stem and progenitor cells. Expert Opin Biol Ther 10: 505-517, 2010.
3. Labusca LS, Botez P, Zugun Eloae F and Mashayekhi K: Stem cells derived from osteoarthritic knee mesenchymal tissues: A pilot study. Eur J Orthop Surg Traumatol 23: 169-176, 2013.

4. Murray IR, West CC, Hardy WR, James AW, Park TS, Nguyen A, Tawonsawatruk T, Lazzari L, Soo C and Péault B: Natural history of mesenchymal stem cells, from vessel walls to culture vessels. Cell Mol Life Sci 71: 1353-1374, 2014.

5. Ogata Y, Mabuchi Y, Yoshida M, Suto EG, Suzuki N, Muneta T, Sekiya I and Akazawa C: Purified human synovium mesenchymal stem cells as a good resource for cartilage regeneration. PloS One 10: e0129096, 2015.

6. De Bari C, Dell'Accio F, Tylzanowski P and Luyten FP: Multipotent mesenchymal stem cells from adult human synovial membrane. Arthritis Rheum 44: 1928-1942, 2001.

7. Imanishi Y, Miyagawa S, Kitagawa-Sakakida S, Taketani S, Sekiya N and Sawa Y: Impact of synovial membrane-derived stem cell transplantation in a rat model of myocardial infarction. J Artif Organs 12: 187-193, 2009.

8. Bernardo ME, Pagliara D and Locatelli F: Mesenchymal stromal cell therapy: A revolution in Regenerative Medicine? Bone Marrow Transplant 47: 164-171, 2012.

9. Arufe MC, De la Fuente A, Fuentes I, de Toro FJ and Blanco FJ: Chondrogenic potential of subpopulations of cells expressing mesenchymal stem cell markers derived from human synovial membranes. J Cell Biochem 111: 834-845, 2010.

10. Fan J, Varshney RR, Ren L, Cai D and Wang DA: Synovium-derived mesenchymal stem cells: A new cell source for musculoskeletal regeneration. Tissue Eng Part B Rev 15: 75-86, 2009.

11. de Sousa EB, Casado PL, Moura Neto V, Duarte ME and Aguiar DP: Synovial fluid and synovial membrane mesenchymal stem cells: Latest discoveries and therapeutic perspectives. Stem Cell Res Ther 5: 112, 2014.

12. Burkandt A, Katzer A, Thaler K, Von Baehr V, Friedrich RE, Rüther W, Amling M and Zustin J: Proliferation of the synovial lining cell layer in suggested metal hypersensitivity. In vivo 25: 679-686, 2011.

13. Chen K, Man C, Zhang B, Hu J and Zhu SS: Effect of in vitro chondrogenic differentiation of autologous mesenchymal stem cells on cartilage and subchondral cancellous bone repair in osteoarthritis of temporomandibular joint. Int J Oral Maxillofac Surg 42: 240-248, 2013.

14. Dominici M, Le Blanc K, Mueller I, Slaper-Cortenbach I, Marini F, Krause D, Deans R, Keating A, Prockop Dj and Horwitz E: Minimal criteria for defining multipotent mesenchymal stromal cells. The International Society for Cellular Therapy position statement. Cytotherapy 8: 315-317, 2006.

15. Nakagawa Y, Muneta T, Kondo S, Mizuno M, Takakuda K, Ichinose S, Tabuchi T, Koga H, Tsuji K and Sekiya I: Synovial mesenchymal stem cells promote healing after meniscal repair in microminipigs. Osteoarthritis Cartilage 23: 1007-1017, 2015.

16. Katagiri H, Muneta T, Tsuji K, Horie M, Koga H, Ozeki N, Kobayashi E and Sekiya I: Transplantation of aggregates of synovial mesenchymal stem cells regenerates meniscus more effectively in a rat massive meniscal defect. Biochem Biophys Res Commun 435: 603-609, 2013.

17. Hatsushika D, Muneta T, Nakamura T, Horie M, Koga H, Nakagawa Y, Tsuji K, Hishikawa S, Kobayashi E and Sekiya I: Repetitive allogeneic intraarticular injections of synovial mesenchymal stem cells promote meniscus regeneration in a porcine massive meniscus defect model. Osteoarthritis Cartilage 22: 941-950, 2014.

18. Sakaguchi Y, Sekiya I, Yagishita K and Muneta T: Comparison of human stem cells derived from various mesenchymal tissues: Superiority of synovium as a cell source. Arthritis Rheum 52: 2521-2529, 2005.

19. Harvanova D, Tothova T, Sarissky M, Amrichova J and Rosocha J: Isolation and characterization of synovial mesenchymal stem cells. Folia Biol 57: 119-124, 2011.

20. Nagase T, Muneta T, Ju YJ, Hara K, Morito T, Koga H, Nimura A, Mochizuki T and Sekiya I: Analysis of the chondrogenic potential of human synovial stem cells according to harvest site and culture parameters in knees with medial compartment osteoarthritis. Arthritis Rheum 58: 1389-1398, 2008.

21. Li Y, Cai H, Fang W, Meng Q, Wu Y, Li J, Deng M and Long X: Triple-layered cell sheet for tissue-engineering the synovial membrane of the temporomandibular joint. Cells Tissues Organs 199: 150-158, 2014.

22. Vandenabeele F, De Bari C, Moreels M, Lambrichts I, Dell'Accio F, Lippens PL and Luyten FP: Morphological and immunocytochemical characterization of cultured fibroblast-like cells derived from adult human synovial membrane. Arch Histol Cytol 66: 145-153, 2003. 
23. Livak KJ and Schmittgen TD: Analysis of relative gene expression data using real-time quantitative PCR and the 2(-Delta Delta C(T)) Method. Methods 25: 402-408, 2001.

24. Friedenstein AJ, Piatetzky S, II and Petrakova KV: Osteogenesis in transplants of bone marrow cells. J Embryol Exp Morph 16: 381-390, 1966.

25. Smith MD: The normal synovium. Open Rheumatol J 5: 100-106, 2011.

26. O'Connell JX: Pathology of the synovium. Am J Clin Pathol 114: 773-784, 2000

27. Iwanaga $T$, Shikichi $M$, Kitamura $H$, Yanase $H$ and Nozawa-Inoue K: Morphology and functional roles of synoviocytes in the joint. Arch Histol Cytol 63: 17-31, 2000.

28. Kung M, Markantonis J, Nelson S and Campbell P: The synovial lining and synovial fluid properties after joint arthroplasty. Lubricants 3: 394-412, 2015.

29. Carvalho de Moraes LO, Tedesco RC, Arraez-Aybar LA, Klein O, Merida-Velasco JR and Alonso LG: Development of synovial membrane in the temporomandibular joint of the human fetus. Eur J Histochemistry 59: 2569, 2015.

30. El-Jawhari JJ, El-Sherbiny YM, Jones EA and McGonagle D: Mesenchymal stem cells, autoimmunity and rheumatoid arthritis. QJM 107: 505-514, 2014.

31. Khan IM, Bishop JC, Gilbert S and Archer CW: Clonal chondroprogenitors maintain telomerase activity and Sox9 expression during extended monolayer culture and retain chondrogenic potential. Osteoarthritis Cartilage 17: 518-528, 2009.

32. Moskalewski S, Osiecka-Iwan A, Jankowska-Steifer E and Hyc A: Synovial membrane asks for independence. Folia Morphol 73: 395-398, 2014

33. Dai L, Pessler F, Chen LX, Clayburne G and Schumacher HR: Detection and initial characterization of synovial lining fragments in synovial fluid. Rheumatology 45: 533-537, 2006.
34. Fickert S, Fiedler J and Brenner RE: Identification, quantification and isolation of mesenchymal progenitor cells from osteoarthritic synovium by fluorescence automated cell sorting. Osteoarthritis Cartilage 1: 790-800, 2003.

35. Gullo F and De Bari C: Prospective purification of a subpopulation of human synovial mesenchymal stem cells with enhanced chondro-osteogenic potency. Rheumatology 52: 1758-1768, 2013.

36. Mochizuki T, Muneta T, Sakaguchi Y, Nimura A, Yokoyama A, Koga $\mathrm{H}$ and Sekiya I: Higher chondrogenic potential of fibrous synovium-and adipose synovium-derived cells compared with subcutaneous fat-derived cells: Distinguishing properties of mesenchymal stem cells in humans. Arthritis Rheumatism 54: 843-853, 2006

37. Dry H, Jorgenson K, Ando W, Hart DA, Frank CB and Sen A: Effect of calcium on the proliferation kinetics of synovium-derived mesenchymal stromal cells. Cytotherapy 15: 805-819, 2013.

38. da Silva Meirelles L, Sand TT, Harman RJ, Lennon DP and Caplan AI: MSC frequency correlates with blood vessel density in equine adipose tissue. Tissue Eng Part A 15: 221-229, 2009.

39. Watt SM, Gullo F, van der Garde M, Markeson D, Camicia R, Khoo CP and Zwaginga JJ: The angiogenic properties of mesenchymal stem/stromal cells and their therapeutic potential. Br Med Bull 108: 25-53, 2013.

40. Li X and Makarov SS: An essential role of NF- $\kappa$ B in the 'tumor-like' phenotype of arthritic synoviocytes. Proc Nat Acad Sci USA 103: 17432-17437, 2006.

This work is licensed under a Creative Commons Attribution-NonCommercial-NoDerivatives 4.0 International (CC BY-NC-ND 4.0) License. 